\title{
INFANTILE ENTERITIS IN DUBLIN CAUSED BY ESCHERICHIA COLI 0142
}

\author{
Rosemary Hone,* S. Fitzpatrick,* C. Keane,* R. J. Gross, $\dagger$ and \\ B. RowE $\dagger$ \\ * Central Microbiology Laboratory, Federated Dublin Voluntary Hospitals, \\ Dublin 8, and \\ $\dagger$ Salmonella and Shigella Reference Laboratory, Central Public Health \\ Laboratory, London NW9 5 HT
}

EARLY in 1971 the services of the Microbiological Laboratory of the Federated Dublin Voluntary Hospitals were extended to include a 92-bed infants' hospital in South Central Dublin. This hospital served a community, most of whom belonged to the lower socio-economic group. The standard of housing was particularly low, overcrowding and poor sanitation being the major problem.

From the beginning of April 1971, faeces or rectal swabs were examined from all infants admitted to the hospital. An attempt was made to assess the occurrence and significance of pathogenic bacteria: Salmonella, Shigella, or enteropathogenic Escherichia coli (EEC). E. coli $\mathrm{O} 142$ had recently been described in outbreaks of infantile enteritis in Scotland (Rowe and Gross, 1971) and antiserum for this type was included in the screening programme.

\section{MATERIALS AND METHODS}

Faecal specimens or rectal swabs with definite faecal staining were cultured by direct plating on deoxycholate-citrate agar and MacConkey agar, and by enrichment in selenite broth with subsequent plating on deoxycholate-citrate agar. Non-lactose-fermenting colonies on any of the plates were tested for urease activity by Christensen's (1946) method, and those giving a negative reaction were identified biochemically according to the tables of Cowan and Steel (1965). Strains of Salmonella and Shigella were identified serologically by slide agglutination and the salmonella species were sent for complete serological identification to the Salmonella and Shigella Reference Laboratory, Colindale.

The MacConkey-agar plates were examined for the presence of EEC by direct slide agglutination of five lactose-fermenting colonies from each plate against the following antisera: (i) polyvalent for $E$. coli O86:B7, O125:B15, O127:B8, O128:B12, O114:K90; (ii) polyvalent for $E$. coli O26:B6, O55:B5, O111:B4, O119:B14, O126:B16; (iii) monovalent for $E$. coli O142: K86.

Strains agglutinated by the polyvalent sera were tested with monovalent antisera, and all positive results were confirmed by tube-agglutination tests on heated suspensions. Strains identified serologically as EEC were then shown to have the biochemical reactions of $E$. coli, and were tested for antibiotic sensitivity by the disk-diffusion method on Diagnostic Sensitivity Test Agar (Oxoid CM261). Disks, made by Mast Laboratories, containing the following antibacterial agents were used: ampicillin $25 \mu \mathrm{g}$, trimethoprim-sulphamethoxazole $2.5 \mu \mathrm{g}$ and $22.5 \mu \mathrm{g}$ respectively, tetracycline $100 \mu \mathrm{g}$, sulphatriad $200 \mu \mathrm{g}$, nitrofurantoin $200 \mu \mathrm{g}$, streptomycin $25 \mu \mathrm{g}$, nalidixic acid $30 \mu \mathrm{g}$, cephaloridine $25 \mu \mathrm{g}$, chloramphenicol $25 \mu \mathrm{g}$, gentamicin $10 \mu \mathrm{g}$, kanamycin $30 \mu \mathrm{g}$, carbenicillin $100 \mu \mathrm{g}$, neomycin $30 \mu \mathrm{g}$, colistin $200 \mu \mathrm{g}$. 
506 ROSEMARY HONE, S. FITZPATRICK, C. KEANE, R. J. GROSS AND B. ROWE

All strains of E. coli $\mathrm{O} 142$ were sent to the Salmonella and Shigella Reference Laboratory, Colindale, for complete serotyping.

TABLE I

Organisms isolated from admission specimens of 460 babies less than 2 years of age

\begin{tabular}{l|cc}
\hline \multicolumn{1}{c|}{ Bacteria isolated } & \multicolumn{2}{|c}{ Number of infants } \\
\cline { 2 - 2 } $\begin{array}{c}\text { with diarrhoea } \\
\text { on admission }\end{array}$ & $\begin{array}{c}\text { without diarhoea } \\
\text { on admission }\end{array}$ \\
\hline $\begin{array}{l}\text { Salmonella } \\
\text { Shigella sonnei } \\
\text { Shigella flexneri } \\
\text { Enteropathogenic } \text { E. coli type }\end{array}$ & 6 & 1 \\
O26 & 2 & 3 \\
O111 & 2 & 0 \\
O119 & 2 & 5 \\
O126 & 2 & 0 \\
O127 & 1 & 2 \\
O114 & 1 & 1 \\
O55 & 1 & 2 \\
O128 & 1 & 2 \\
O86 & 1 & 2 \\
O142 & 13 & 2 \\
No pathogens & 37 & 370 \\
\hline Total number of patients & 70 & 390 \\
\hline
\end{tabular}

TABLE II

Organisms isolated from 54 babies who developed an attack of diarrhoea after admission

\begin{tabular}{l|cc}
\hline \multicolumn{1}{c|}{ Bacteria isolated } & $\begin{array}{c}\text { Number of infants from whom } \\
\text { organism was isolated }\end{array}$ \\
& on admission & $\begin{array}{c}\text { during subsequent } \\
\text { diarrhoea }\end{array}$ \\
\hline Salmonella stanleyville & 0 & 2 \\
Shigella sonnei & 0 & 1 \\
Shigella flexneri & 0 & 1 \\
Enteropathogenic E. coli type & 1 & 2 \\
O26 & 0 & 6 \\
O55 & 0 & 1 \\
O111 & 1 & 0 \\
O126 & 0 & 1 \\
O128 & 1 & 0 \\
O142 & 0 & 40 \\
No pathogens & 51 & 7 \\
\hline
\end{tabular}

\section{Results}

Bacteriology. Admission specimens from 460 patients under $2 \mathrm{yr}$ of age were examined from April 1971 until October 1971. Of these patients, 70 (18 per cent.) presented with diarrhoea and vomiting, the most common single 
causative organism being $E$. coli 0142 , which was isolated from 13 patients. These results are summarised in table $I$.

Diarrhoea occurring after admission to hospital was found in 54 (14 per cent.) of the 390 patients who were without diarrhoea on admission. Admission specimens of this group showed that one patient excreted $E$. coli 026 , one

\section{TABLE III}

Isolation of pathogens from 54 babies who developed an attack of diarrhoea after admission to hospital

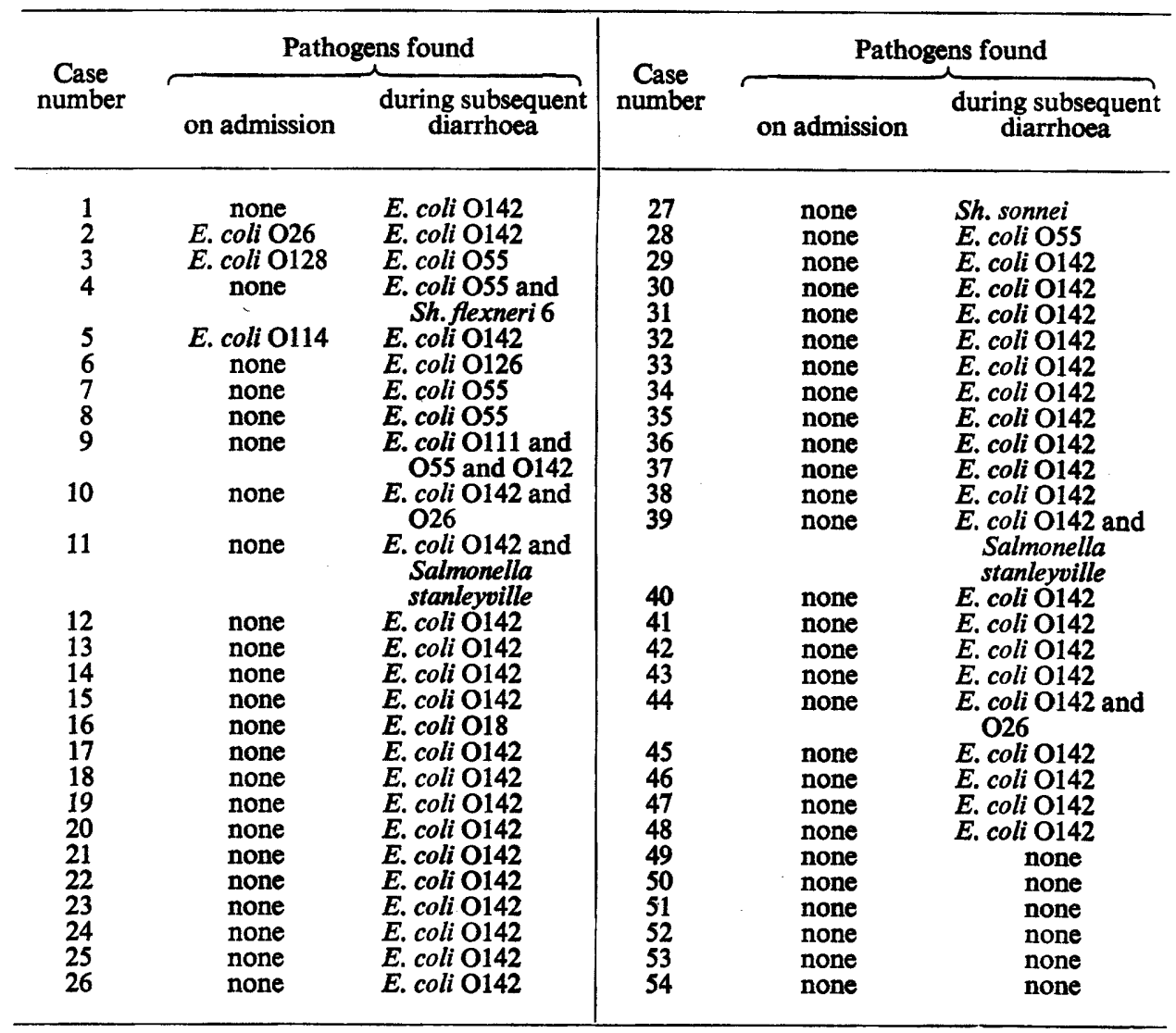

excreted $E$. coli $\mathrm{O} 114$, and another excreted $E$. coli 0128 ; these serotypes were not isolated at the time of the hospital-acquired diarrhoea, but $E$. coli O142 was isolated from two of these patients. Six other patients had multiple infections. In all, $E$. coli 0142 was isolated from 40 of the 54 patients at the time of their hospital-acquired diarrhoea. These findings are summarised in table II, and the results for individual patients are shown in table III.

Fourteen patients who presented with diarrhoea recovered and subsequently developed a second attack while in hospital. This is referred to as a recurrence 
of diarrhoea. Their bacteriological findings are shown in table IV. Twelve contacts of infected patients became symptomless excretors.

Further examination of $E$. coli 0142 strains showed that they were all of serotype O142:K86:H6, resistant to ampicillin, tetracycline, sulphatriad, neomycin, kanamycin, and carbenicillin. Two of the strains were also resistant to trimethoprim-sulphamethoxazole. All strains were biochemically atypical in that they failed to produce indole in peptone-water cultures.

Symptoms. All cases occurred in infants under 1 year of age and more than half of them were less than $4 \mathrm{mth}$ old; 63 per cent. of them were males.

TABLE IV

Pathogens isolated from 14 babies who were admitted with diarrhoea and had a recurrence of diarrhoea

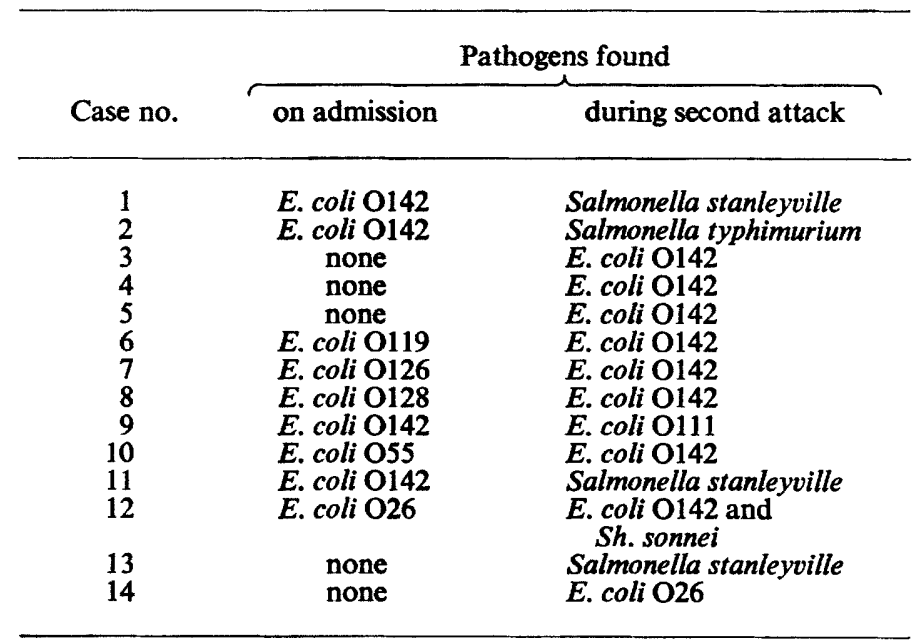

Many patients were poorly nourished, coming from poor and overcrowded homes. Anaemia and respiratory-tract infections are among the commonest causes for admission to hospital. Cases were divided into three grades according to the severity of the symptoms.

Mild cases (grade I) had loose stools and occasional vomiting. There was no dehydration, and oral feeding was maintained. Eight infants with diarrhoea on admission and 43 with hospital-acquired infection were in this grade. Thirtysix of them had a respiratory-tract infection.

Moderately ill patients (grade II) had fluid motions and vomiting. There was mild dehydration; oral feeding was maintained. This was equivalent to grade I of Ironside, Tuxford and Heyworth (1970). Four admission cases and six hospital-acquired infections were in this group; four of them had a respiratorytract infection.

Severely ill patients (grade III) had vomiting and diarrhoea with dehydration, which necessitated parenteral fluid replacement. This was grade II of Ironside et al. One six-week-old male was in this group, and he also had slightly raised 
alanine and aspartate transaminases which returned to normal after symptoms subsided.

Antibacterial therapy before infection. Of the 49 patients who became infected with $E$. coli $O 142$ in hospital, 39 were being treated with antibacterial agents at the time of infection or just before the onset of infection. Fifteen were receiving penicillin V, 13 ampicillin, four erythromycin, six trimethoprimsulphamethoxazole (Bactrim), and one was receiving kanamycin.

Period of excretion. The period of excretion of E. coli $\mathrm{O} 142$ was determined in 52 cases. Twenty-eight excreted the organism for 5 days, 17 for 10 days, and the remaining seven for between 10 and 30 days. All 52 had received antibacterial therapy.

Cross-infection with $E$. coli O142. Cases occurred in three wards, two of which shared staff and kitchen facilities. Each patient was barrier nursed, but only one ward had cubicles. Undoubtedly cross-infection occurred within the wards and between them. One nurse who prepared feeds was found to excrete $E$. coli $\mathrm{O} 111$, but no carriers of $E$. coli $\mathrm{O} 142$ were found amongst the staff.

Numerous air samples and environmental swabs were examined and $E$. coli O142 was isolated from a locker top in one ward and a cot rail in another.

By mid-October the outbreak had subsided and no more new cases occurred within the hospital. An analysis of the hospital-acquired cases showed that the infection prolonged their stay in hospital on average by 10 days.

\section{Discussion}

E. coli $\mathrm{O} 142: \mathrm{K} 86: \mathrm{H} 6$ was first isolated from infants with diarrhoea in Indonesia (Ørskov et al. 1960), later from an outbreak of diarrhoea amongst premature infants in a Mexican hospital (Olarte and Ramos-Alvarez, 1965), and recently from outbreaks in the British Isles (Rowe and Gross, 1971; Roberts et al., 1971). In the present study, this serotype was isolated from 13 (18.6 per cent.) of 70 patients admitted with diarrhoea but only two ( 0.5 per cent.) of 390 admitted without diarrhoea. Among 68 cases of diarrhoea acquired after admission to hospital, E. coli $\mathrm{O} 142$ was found in 49 (72 per cent.). It is clear that this serotype was a cause of diarrhoeal disease in the community served by the hospital and was also the cause of a cross-infection outbreak within the hospital during the period of study.

Few of the infections in this outbreak were severe. It was significant that none of the babies had serious underlying illness or was premature-factors regarded as important in determining the outcome of infantile enteritis in recent years (Taylor, 1970).

Cross-infection was an important factor in the outbreak, despite barrier nursing. Once an EEC is introduced into a unit housing young infants, the spread of infection is difficult to prevent even with adequate cubicle accommodation. During an outbreak an admission policy is an essential safeguard; Taylor recommends that all babies should remain in isolation until bacteriological tests are complete. No such policy was in force during this survey. 


\section{SUMMARY}

Faeces or rectal swabs were taken from 460 patients under the age of 2 yr on admission to a Dublin paediatric hospital. Of the 460,70 had diarrhoea and 390 were without diarrhoea on admission. The results of bacteriological examination of the specimens gave an indication of the range of enteropathogenic organisms causing disease in the community served by the hospital.

Of the 390 patients admitted without diarrhoea, 54 subsequently developed it; and of the 70 admitted with diarrhoea, 14 developed a second attack after recovering from the first. Examination of specimens from the 68 infants who developed diarrhoea after admission to hospital indicated the degree and pattern of cross-infection within the hospital. The importance of Escherichia coli O142:K86:H6 as a cause of diarrhoea during the survey was clearly demonstrated.

We are grateful to the medical and nursing staff of the hospital who gave us their fullest co-operation throughout this work. This study was supported in part by a grant from the Pathology Development Fund of the Federated Dublin Voluntary Hospitals.

\section{REFERENCES}

Christensen, W. B. 1946. Urea decomposition as a means of differentiating proteus and paracolon cultures from each other and from Salmonella and Shigella. J. Bact., 52, 461.

Cowan, S. T., AND SteEL, K. J. 1965. Manual for the identification of medical bacteria, London, p. 72-74.

Ironside, A. G., TuXford, A. F., AND HeYworth, B. 1970. A survey of infantile gastroenteritis. Br. Med. J., 3, 20.

Ørskov, F., Ørskov, IDA, Rees, T. A., AND SAHAB, K. 1960. Two new E. coli O-antigens: O141 and 0142 and two new coli K-antigens: K85 and K86. Acta path. microbiol. scand., 48, 48.

Olarte, J., AND Ramos-Alvarez, M. 1965. Epidemic diarrhea in premature infants. Am. J. Dis. Child., 109, 436.

Rowe, B., AND Gross, R. J. 1971. E. coli 0142 and infantile enteritis in Scotland. Lancet, $1,649$.

Roberts, W., Shrivastava, S. C., Emslie, J. A. N., and Ingham, H. R. 1971. E. coli 0142 and infantile enteritis in Scotland. Lancet, 1, 757.

TAYLOR, JOAN 1970. Infectious infantile enteritis, yesterday and to-day. Proc. R. Soc. Med., $59,607$. 